\section{A new way to motivate your patients}

Interest and engage your patients in a completely unique and fascinating way. Shift any negative perceptions of dentistry, build rapport, and help patients to realise the benefits of good oral health with the innovative Calcivis imaging system.

Calcivis is the first biotech product in the world to be used in dentistry: it applies a photoprotein to detect free calcium ions on the tooth surface and captures a glowing, visual map of active demineralisation at the chair side.

Calcivis acts as an early detection system that supports preventive and minimally invasive dentistry. It allows dental professionals to identify active demineralisation at its earliest and most reversible stages and provides an extremely effective communication tool that enables practitioners to deliver personalised information to each and every patient.

The Calcivis imaging system offers patient-centred education to increase understanding, motivation and reassurance. In this way many of the fears regarding the dental visit can be dispelled to add value and enhance the patient/practitioner relationship.
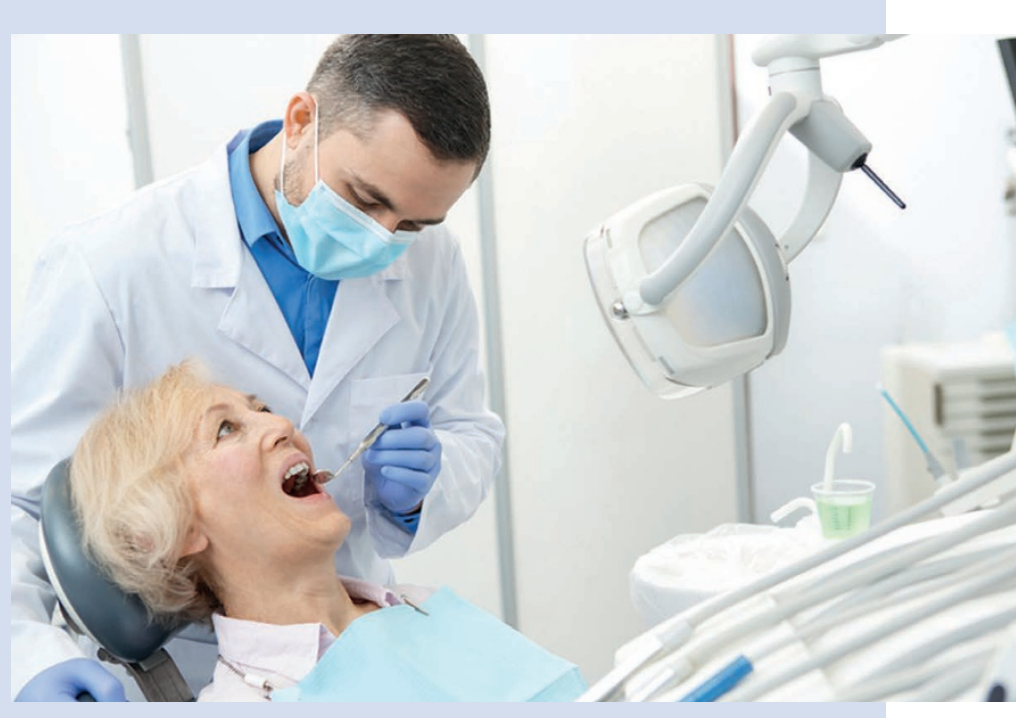

To find out more about Calcivis visit www.CALCIVIS.com or call 01316585152.

\title{
Consistently high quality care
}

Who do you turn to if you are unable to offer specialist treatment? Consider referring cases to award-winning Ten Dental, who has gained an outstanding reputation for being one of the UK's most trusted referral centres.

Comprised of implantology experts and specialists in endodontics, periodontics and orthodontics, the team at Ten Dental have the experience and facilities to handle complex referral cases. Spearheaded by renowned implantologists, Drs Martin Wanendeya and Nik Sisodia, you'll have peace of mind knowing patients are in the hands of experts.

Accustomed to operating alongside referring practitioners to achieve successful outcomes, the Ten Dental team will always keep you well informed of patients' progress during any procedure. They will also offer ongoing support and advice to enable you to provide the optimum care at each stage of treatment.

Work with Ten Dental at one of its three state-of-the-art clinics in London to ensure your patients receive consistent and high quality service, no matter what procedures they need.

For more information visit www.tendental.com or call on 02033932623

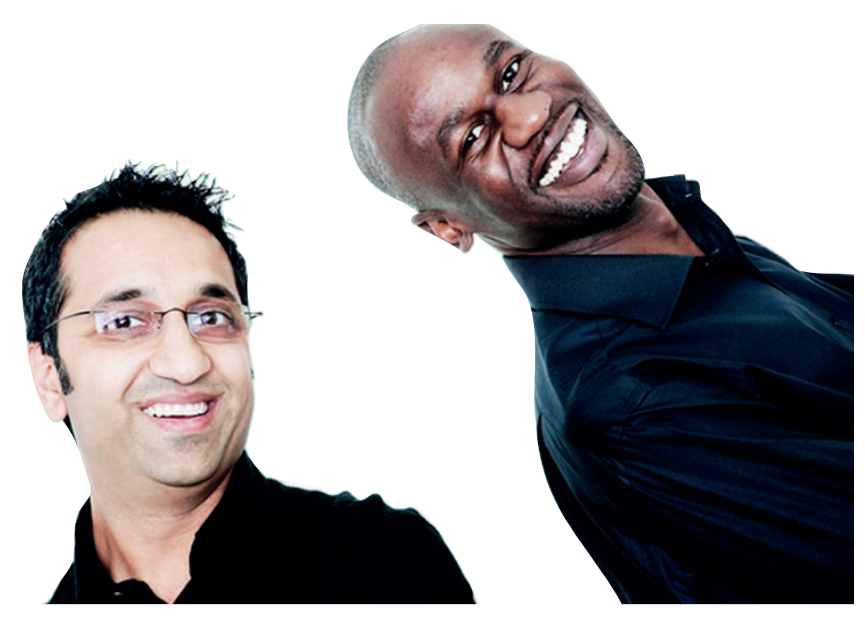

\section{One big happy family}

Since being established over 16 years ago, MediHoldings has become the largest specialist broker of UK dental practices through MediEstates, the largest UK dental recruitment agency through MediCruit and specialist financial advisers to the dental profession through MediFinancial. In April 2017 the company announced it was to become a part of an even bigger family when they were acquired by Henry Schein, one of the world's largest distributors of healthcare products, services and supplies.

Becoming a part of the Henry Schein family means the Medi group of companies is now better placed than ever to understand the challenges of the dental profession and provide industryleading services through the combined offerings of Henry Schein
Dental and Software of Excellence, also a Henry Schein company.

Henry Schein has touch-points in almost every dental practice in the UK and the fact that MediEstates, MediCruit and MediFinancial are now a part of this network only adds to their already extensive knowledge of the dental market. Added to this is the ability to share performance data from Software of Excellence, further enabling the team at MediEstates to have an even greater insight into practice potential, fuelling the ability to advise practice owners how they can maximise the value of their practice

If you would like further information on any of the services provided by the Medi group of companies, call 01332 609318, email contact@mediestates.co.uk or visitwww.mediestates.co.uk. 